\title{
CHILDREN ENDORSE DETERRENCE MOTIVATIONS FOR THIRD-PARTY PUNISHMENT BUT DERIVE HIGHER ENJOYMENT FROM COMPENSATING VICTIMS
}

Rhea L. Arini ${ }^{1,2}$, Marukh Mahmood ${ }^{2}$, Juliana Bocarejo Aljure ${ }^{3}$, Gordon Ingram ${ }^{3}$, Luci Wiggs $^{2}, \&$ Ben Kenward ${ }^{2}$

${ }^{1}$ School of Anthropology and Museum Ethnography, University of Oxford, UK

${ }^{2}$ Centre for Psychological Research, Oxford Brookes University, UK

${ }^{3}$ Department of Psychology, Los Andes University, Bogotá, Colombia 3

Correspondence should be addressed to: Rhea L. Arini (rhea88bg@gmail.com)

Data, script, stimuli, analysis pipelines are available at Open Science Framework: https://osf.io/4ygw5/

(1)

(1)

0

1

2

3

4

5

6

7

8


Abstract

Children's punishment behaviour may be driven by both retribution and deterrence, but the potential primacy of either motive is unknown. Moreover, children's punishment enjoyment and compensation enjoyment have never been directly contrasted. Here, British, Colombian and Italian 7- to 11-year-old children $(\mathrm{N}=123)$ operated a Justice System in which they viewed different moral transgressions in Minecraft, a globally popular videogame, either face-to-face with an experimenter or over the internet. Children could respond to transgressions by punishing transgressors and compensating victims. The purpose of the system was framed in terms of retribution, deterrence, or compensation, between subjects. Children's performance, endorsement and enjoyment of punishment and compensation were measured, along with their endorsement of retribution vs. deterrence as punishment justifications, during and/or after justice administration. irrespective of age. When asked to reproduce the presented frame in their own words, children more reliably reproduced the deterrence than retribution frame. Punishment enjoyment decreased while compensation enjoyment increased over time. Despite enjoying compensation more, children preferentially endorsed punishment over compensation, especially with increasing age and transgression severity. Reported deterrent justifications, superior reproduction of deterrence framing, lower enjoyment of punishment than compensation, and higher endorsement of punishment over compensation together suggest that children felt they ought to mete out punishment as a means to deter future transgressions. Face-to-face and internet-mediated responses were not distinguishable, supporting a route to social psychology research with primary school-aged children unable to physically visit labs.

52 of third-party interventions; punishment motives 


\section{General Introduction}

54 When violations of moral norms occur, there is a tension between different possible 55 courses of action that can satisfy the psychological need to see justice restored. Witnessing norm 56 transgressions can trigger at least two different - although non-mutually exclusive - types of 57 third-party interventions: punishment of transgressors (i.e., third-party punishment) and/or 58 compensation of victims. Whereas punitive justice has received a great deal of academic 59 attention, compensatory justice still lags behind (but see Gummerum et al., 2016; Petersen et al., 60 2012). Although some large-scale societies have moved towards increased use of reparative 61 justice within penal systems in recent decades (including compensation, Johnstone \& Van Ness, 62 2013), the focus remains on punitive sanctions. This is striking in light of anthropological 63 evidence documenting that small-scale societies do not commonly adopt punishment to solve 64 disputes (Marlowe et al., 2007), but they more frequently involve third-parties in processes of 65 mediation and arbitration. These forms of triadic settlements are aimed at promoting 66 reconciliation between the antagonists, or at rendering decisions about compensation of the

67 wronged party (Fry, 2000; Singh \& Garfield, 2022). Moreover, whereas third-party punishment 68 seems to be a uniquely human behaviour (Riedl et al., 2012), ethologists have observed triadic 69 post-conflict affiliations directed towards victims of aggressions in non-human primates (Fraser 70 et al., 2009), some of which might be considered the evolutionary bases of human compensation. The number of empirical papers on children's third-party punishment has reached double

72 digits in the last years (see Marshall \& McAuliffe, 2022 for a review). However, very few 73 developmental studies have simultaneously tested different types of third-party interventions in 74 response to moral transgressions (reviewed below). Thus, we investigate here a range of factors 75 that could potentially modulate children's choices between punishment and compensation, the 
affective states following the enactment of these two types of third-party interventions, as well as

77 the motivational basis of punishment. Given that most of the literature on children's third-party interventions has been conducted in Northern European and Northern American countries (but

79 see Yang et al., 2021 and Liu et al., 2021), we included children from three different countries

80 (UK, Italy and Colombia) to increase diversity in the sample. Our analysis focuses on 81 commonalities rather than differences across countries.

\section{Third-Party Interventions: Compensation and Punishment}

One line of research has put the two types of third-party interventions in direct comparison to establish if people tend to be compensation- or punishment-oriented. In the adult literature, some studies have provided evidence for preference for punishment (Adams \& Mullen, 2015; van Prooijen, 2010), others for compensation (Chavez \& Bicchieri, 2013; Lotz et al., 2011; Van Doorn, Zeelenberg, \& Breugelmans, 2018; Van Doorn, Zeelenberg, Breugelmans et al., 2018). These mixed results might be due to whether the third-party intervention options at compensate instead of punishing, both punishment and compensation were economically costly to the participants. In contrast, in studies showing preference for punishment over compensation there were no costs associated with either type of third-party intervention. This could be due to participants acting upon intuition rather than deliberation when they can carry out third-party interventions at no cost to themselves (Van Doorn \& Brouwers, 2017).

There are now a handful of studies that have investigated children's compensatory and punitive tendencies simultaneously. In one such study, 9- to 22-year-old Dutch participants witnessed instances of social exclusion, and then played economic games with the victims and transgressors. Older participants paid greater costs to compensate victims and punish 
transgressors, but it was not possible to establish whether participants preferred compensation or 100 punishment, because the two were not contrasted directly (Will et al., 2013). Other 101 developmental studies were explicitly designed to assess if children tend to be compensation- or 102 punishment-oriented. However, in contrast to the adult literature, it is challenging to identify 103 systematic patterns, in part because compensation was differently operationalised across studies. make up for the transgression they suffered, while the transgressor's payoff is left untouched. For example, in hypothetical scenarios involving physical harm, 7- to 12-year-old Canadian children were more willing to see the transgressor being punished than the victim being compensated, 108 irrespective of age, with this tendency becoming more pronounced for more severe 109 transgressions (Miller \& McCann, 1979). Conversely, after witnessing third-party interventions 110 in response to inequity (i.e., selfish resource distributions), 5- to 9-year-old US children 111 evaluated compensation more positively than punishment, regardless of their age (Lee \& 112 Warneken, 2020). However, when given the choice to intervene themselves in response to 113 inequity, 6- to 9-year-old US children were more likely to pay a cost to enact punishment than 114 compensation (McAuliffe \& Dunham, 2021).

115 In another line of research employing ownership transgressions such as theft, punishment 116 was pitted against restitution. Restitution confounds compensation and punishment since the 117 action of returning the resources to the victim also affects the transgressor's payoff. These 118 studies all used non-incentivised paradigms, where children did not have to pay a cost to enact 119 their preferred intervention. For example, in response to theft, 3-year-old German children 120 preferred to return stolen resources to the victim (i.e., restitution) rather than just making them 121 inaccessible to both the thief and the victim (i.e., punishment) or doing nothing (Riedl et al., 
122 2015). In another experiment, 3- to 6-year-old Chinese children also preferred to enact restitution

123 over punishment but in this case punishment entailed taking away even the resources that the

124 transgressors had prior to the theft (Yang et al., 2021). Finally, when witnessing victims'

125 reactions to ownership transgressions, 4- to 6-year-old Chinese children evaluated restitution

126 more positively than punishment, especially in case of harsh punishment (Liu et al., 2021).

127 We did not operationalise compensation as restitution. Rather, compensation entailed 128 providing the victim with resources to make up for the damage endured, while the transgressor's 129 payoff remained unchanged. Our research intended to expand knowledge about whether 130 children's orientation for punishment or compensation is modulated by factors such as 131 judgement of transgression severity, transgression type and children's age. In order to assess 132 orientation, we measured punishment vs. compensation endorsement via forced-choice self133 report tasks, after children had the opportunity to enact both compensation and punishment 134 behaviours. However, we did not assess children's orientation by comparing levels of 135 compensation and punishment because our paradigm used different currencies for each (material 136 resources for compensation; time-outs for punishment).

Specifically, we investigated whether endorsement of compensation vs. punishment 138 would change as a function of how seriously children judged transgressions (Q1, Table 1). Since 139 Miller and McCann (1979) showed that children's preference for punishment over compensation 140 was higher in response to severe transgressions compared to mild transgressions, we expected to 141 observe children increasingly endorsing punishment over compensation the more severely they 142 judged the transgressions.

We were also interested in whether punishment vs. compensation endorsement would be 144 affected by the type of moral transgression (Q2, Table 1). We predicted children would attribute 
145 more importance to punishment in case of physical harm (Miller \& McCann, 1979), and to 146 compensation in case of ownership transgressions such as theft (Riedl et al., 2015; Yang et al., 147 2021; Liu et al., 2021). We were less confident in making predictions about the effect of inequity 148 transgressions, given the lack of relevant literature at the time of developing our experiment 149 (contrasting findings were published later, see Lee \& Warneken, 2020 and McAuliffe \& 150 Dunham, 2021). However, it seemed plausible that children would preferentially endorse 151 compensation in response to inequity, as there is evidence that children are motivated to 152 intervene as third parties by the desire to even out the resource imbalances experienced by 153 victims (Arini et al., 2021). Importantly, in our paradigm resource imbalances could be corrected 154 only via compensation, not punishment. Because of our interest in both transgression type and 155 transgression severity judgement, which are likely to be associated, we examine their 156 independent effects using models controlling for both.

157 Finally, we tested whether children's endorsement of punishment vs. compensation was 158 dependent on age (Q3, Table 1). Since Riedl et al. (2015) demonstrated that third-party 159 interventions in early childhood are compensation-oriented, whereas Miller \& McCann (1979) 160 showed that third-party interventions in middle- to late childhood are punishment-oriented, we 161 hypothesised there might be a shift towards endorsement of punishment over compensation with 162 increasing age. We note that this is also consistent with some more recent studies that were not 163 available when we designed our experiment (Yang et al., 2021; McAuliffe \& Dunham, 2021; Liu 164 et al., 2021).

\section{Affective States Induced by Third-Party Interventions}

It is unclear whether individuals' endorsement of punishment vs. compensation is aligned

167 to enjoyment of punishment vs. compensation. A misalignment (i.e., preferential endorsement of 
168 punishment accompanied by higher enjoyment of compensation) would suggest that individuals 169 see punishment as a moral duty, something that ought to be done (Arini et al., 2021).

Neuroscientific studies have begun to clarify the affective components involved in

171 punishment and compensation in adults. The activation of the striatum, a key area in the brain's

172 reward circuitry, seems to reflect anticipatory satisfaction. This kind of striatal response has been

173 observed both in people meting out punishment (Strobel et al., 2011) and compensation (Hu et 174 al., 2015). Activation of the striatum predicts charitable donations to victims of misfortune 175 (Genevsky et al., 2013; Harbaugh et al., 2007).

Research focused on adults' subjective reports of punishment-related emotions has

177 instead produced somewhat mixed results. People confronted with a cooperative norm violation

178 predicted that taking revenge would make them feel better. However, once they enacted 179 punishment, they ended up reporting lower mood (due to rumination) than those who had not 180 punished (Carlsmith et al., 2008). It has been shown that, for people to derive satisfaction from 181 punishment, it is important to know how the transgressor reacts to the punishment. Indeed, 182 punishers reported to be satisfied if they saw the transgressor suffer because of punishment, 183 and/or if they received proof that the transgressor learnt a lesson through punishment (Aharoni et 184 al., 2022). Avengers experienced higher levels of satisfaction than non-avengers upon receiving 185 a message from the transgressor that acknowledged that they had understood why they had been 186 punished (Gollwitzer \& Denzler, 2009; Gollwitzer et al., 2011) or that indicated a change in 187 moral attitude (Funk et al., 2014). Nevertheless, people showed no increased willingness to 188 punish at the prospect of receiving information on the effects of punishment on the transgressor 189 (Funk \& Mischkowski, 2022). This may suggest that people fail to predict what would bring 190 them satisfaction following a moral transgression. 
Given the gap in knowledge about children's affective states related to third-party 192 interventions, scientific efforts have now begun focussing on the study of the emotional 193 antecedents and consequences of children's punishment behaviour. Regarding the emotional 194 antecedents of punishment, self-reported anger after witnessing inequity has been shown to 195 mediate the link between transgression severity and costly punishment in British adults but not in 196 children and adolescents (Gummerum et al., 2020). Moreover, by experimentally manipulating 197 anger (via an autobiographical recall procedure), it was possible to demonstrate that anger has a 198 causal role on punishment severity of inequity in British adults and adolescents but not in 199 children (Gummerum et al., 2022). Regarding the emotional consequences of punishment, 5- to 200 7-year-old US children who meted out punishment reported higher levels of sadness, and lower 201 levels of happiness and excitement than their peers who did not punish (see Supplemental 202 Material in Marshall et al., 2021). Moreover, 5- to 11-year-old British children were more likely 203 to report no enjoyment when they enacted real rather than pretend punishment (Arini et al., 204 2021).

205 In the current study we investigated whether enjoyment would vary according to the type 206 of third-party intervention children were enacting (Q4, Table 1), and to the time passed since the 207 intervention (Q5, Table 1). We measured enjoyment immediately after children decided how to 208 respond to transgressions, and then again, once they had the time to reflect upon their past 209 choices at the end of the experiment. Notably, children were told that their punishment and 210 compensation decisions would be implemented. However, children were neither shown how the 211 transgressors and victims reacted to their decisions, nor were they made think that they would 212 receive such information. Since children could not ascertain whether the transgressors suffered 213 or learnt a moral lesson through punishment, we expected children not to derive satisfaction from 
214 punishment. Therefore, we predicted that compensation would generally elicit more enjoyment

215 than punishment. Furthermore, based on Carlsmith at al.'s (2008) findings about the negative

216 effect of punishment-induced rumination on adults' affective states, we expected that children's

217 punishment enjoyment would decrease across time. Since it has been previously demonstrated

218 that British children's emotional experience of punishing was on average neither positive nor

219 negative when measured at the end of the experiment (Arini et al., 2021), we predicted we would

220 find comparable results also in the current study at the same time point. However, we did not

221 formulate any specific prediction for the temporal pattern compensation enjoyment would

222 follow.

\section{Punishment Motives and Justifications: Deterrence and Retribution}

Clarifying what people feel when they engage in punishment could help explain why

225 people punish (but see discussion in Funk \& Mischkowski, 2022). The philosophical literature

226 about the motivational basis of punishment can be organised around two main theories of justice:

227 retribution and deterrence. Retributive punishment is rooted in balancing out a past injustice by

228 giving the transgressor their "just deserts" (Kant, 1790/1952). In contrast, deterrence

229 conceptualises punishment as a means to prevent future misbehaviours by transgressors and/or

230 bystanders (Bentham, 1789/1948). Thus, retribution theory is in accord with the idea that

231 punishment is motivated by the desire to see the transgressors suffer in proportion to the

232 wrongdoing committed (suffering hypothesis). Instead, deterrence theory is in accord with the

233 idea that punishment is aimed at communicating to the transgressors that they should make

234 amends for their misbehaviour (understanding hypothesis) (Berman, 2010).

235

Psychological research has demonstrated that adults are motivated by both retribution and

236 deterrence, but with retribution probably more important. For example, manipulating punishment 
237 severity (as retribution-relevant information) increased participants' punitive tendencies, yet 238 manipulating punishment observability (as deterrence-relevant information) did not (Carlsmith et 239 al., 2002; Mohlo et al., 2022). Relatedly, before making punishment recommendations people 240 were most likely to first seek retribution-relevant information as it increased their confidence in 241 the appropriateness of their decisions more than deterrence-relevant information (Carlsmith, 242 2006; Keller et al., 2010). Moreover, it has been shown that adults were more willing to invest 243 resources into punishing transgressors when punishment satisfied only retributive motives, 244 compared to when it satisfied a combination of deterrent and retributive motives (Nockur et al., 245 2022; but see Crockett et al., 2014).

In the adult literature, a remarkable discrepancy has been noticed between people's actual 247 punitive choices (which tend to be retribution-oriented) and their explicit justifications (which 248 tend to be deterrence-oriented). People have been shown to support deterrence policies in the 249 abstract but reject them once they saw them contradicting retributive principles (Carlsmith, 250 2008). People were also shown to persist in justifying their punishment recommendations in 251 deterrent terms, even if they were pointed out that none of their justifications were applicable to 252 the specific scenario (Aharoni \& Fridlund, 2012). People invested resources into retribution of 253 transgressions more often than they reported endorsing retributive justifications (Crockett et al., 254 2014). This mismatch between implicit punishment motivations and explicit justifications may 255 be driven by people's lack of insight into, or inability to express, the motivations of their own 256 behaviour (Carlsmith, 2008). An implication of this argument is that deterrent justifications are 257 primarily post-hoc rationalisations of retributive impulses (Aharoni \& Fridlund, 2012; Keller et 258 al., 2010; Carlsmith \& Darley, 2008; but see Rehren \& Zisman, 2022). This mismatch could also 259 indicate the existence of a social desirability bias, since adults may be aware that being perceived 
as aggressive can have a detrimental effect on their reputation (Eriksson et al., 2016; Raihani \& Bshary, 2015a; Gordon et al., 2014).

Regarding the developmental literature, both interview and experimental studies have shown that children are capable of deterrence reasoning from a young age, at least in US contexts. Stern \& Peterson (1999) analysed how 4- to 11-year-old children justify their punishment choices in response to a variety of transgressions. Children of all ages were equally likely to use eye-for-an-eye justifications. However, starting from 7-8 years of age, children began to also show awareness of the preventive function of punishment. Bregant et al. (2016) presented 5- to 8-year-old children with a scenario depicting a character stealing a resource from another character. The theft either remained unpunished or was followed by a punishment (not decided by the children themselves). Children predicted that the punished thief would be less likely to misbehave again than the unpunished thief. Dunlea \& Heiphetz (2021) found that 6- to 8-year-old children - but not adults - report that "mean" people become "nicer" after both severe and mild forms of punishment (incarceration and time-out, respectively). In Yudkin et al.'s (2019) study, 3- to 6-year-old children could decide whether to engage in punishment by preventing a harmful peer from accessing a playing opportunity. Once questioned about the reasons for their punitive decisions, they mentioned the desire to see the transgressor change their behaviour and learn a lesson. Importantly, these expressions of desire for reform correlated with children's actual punishment rates.

Regarding the motivational basis of punishment, there is evidence that, already from early childhood, children prefer to see bad things happen to those who behave badly towards others (Hamlin et al., 2011; Kenward \& Östh, 2012, 2015), suggesting incipient retributive desires or expectations. However, a couple of recent studies conducted on older participants (4- 
283 to 7-year-old US children and 9- to 12-year-old German children) suggests that children can be 284 motivated by both deterrence and retribution. There is indeed evidence that children punished 285 transgressors at higher rates and invested more resources into punishment when doing so 286 satisfied both retributive and deterrent motives, compared to when it satisfied purely retributive 287 motives (Marshall et al., 2021; Twardawski \& Hilbig, 2020). In the face of a large body of 288 evidence suggesting that adults are often motivated by retribution despite the deterrent 289 justifications they provide, but more limited evidence in children, it is still unclear whether this 290 mismatch between implicit punishment motivations and explicit justifications is also present 291 when children punish.

Regarding the implicit motivations of punishment, we explored whether children's 293 punishment severity would change depending on the type of punishment frame they had been 294 experimentally assigned to (Q6, Table 1), i.e., whether children's role as third-party punishers 295 was framed as serving a deterrent or retributive purpose. We argue that the punishment frame 296 most in line with children's pre-existing punishment motivation would also be the most effective 297 at increasing their punishment severity (for a similar paradigm, see van Prooijen, 2010). Since 298 there were few grounds for a specific prediction as to whether children are primarily motivated 299 by deterrence or retribution, we did not make one.

300 Regarding the explicit justifications of punishment, we analysed how children justified 301 the punishment behaviours they had meted out. More specifically, we assessed endorsement of 302 deterrence or retribution in a forced-choice task, expecting to observe increasing rates of 303 deterrence endorsement with age (Q7, Table 1), consistently with Stern \& Peterson's (1999) 304 findings. Since it has been argued that retribution is driven by intuition and deterrence by 305 deliberation (Aharoni \& Fridlund, 2012; Keller et al., 2010; Carlsmith \& Darley, 2008; but see 
Rehren \& Zisman, 2022), we predicted that younger children would endorse retribution more often than older children due to their relative lack of inhibitory control and forward-looking reasoning skills.

\section{Method Validation: Setting Method and Believability} compare results obtained in each way. We additionally checked that the Minecraft Justice

Table 1. Research questions, related predictions, and whether data supported predictions

\begin{tabular}{|c|c|c|c|}
\hline Topic & Research question & Prediction & Supported? \\
\hline \multirow[t]{4}{*}{$\begin{array}{l}\text { Third-Party } \\
\text { Interventions: } \\
\text { Compensation and } \\
\text { Punishment }\end{array}$} & $\begin{array}{l}\text { Q1 (a priori): Does participants' } \\
\text { judgement of transgression severity } \\
\text { affect compensation vs. punishment } \\
\text { endorsement (during justice } \\
\text { administration)? }\end{array}$ & $\begin{array}{l}\text { More severe judgements lead } \\
\text { to higher endorsement of } \\
\text { punishment over } \\
\text { compensation. }\end{array}$ & Yes \\
\hline & \multirow[t]{2}{*}{$\begin{array}{l}\text { Q2 (a priori): Does transgression } \\
\text { type affect compensation vs. } \\
\text { punishment endorsement (during } \\
\text { justice administration)? }\end{array}$} & $\begin{array}{l}\text { Physical harm elicits higher } \\
\text { endorsement of punishment } \\
\text { over compensation. }\end{array}$ & No \\
\hline & & $\begin{array}{l}\text { Theft and inequity elicit } \\
\text { higher endorsement of } \\
\text { compensation over } \\
\text { punishment. }\end{array}$ & No \\
\hline & $\begin{array}{l}\text { Q3 (a priori): Does children's age } \\
\text { affect compensation vs. punishment } \\
\text { endorsement (during and after } \\
\text { justice administration)? }\end{array}$ & $\begin{array}{l}\text { Endorsement of punishment } \\
\text { over compensation increases } \\
\text { with increasing age. }\end{array}$ & $\begin{array}{l}\text { Yes (but only after } \\
\text { justice } \\
\text { administration) }\end{array}$ \\
\hline
\end{tabular}




\begin{tabular}{|c|c|c|c|}
\hline \multirow[t]{3}{*}{$\begin{array}{l}\text { Affective States } \\
\text { Induced by Third- } \\
\text { Party Interventions }\end{array}$} & $\begin{array}{l}\text { Q4 (a priori): Does type of third- } \\
\text { party intervention affect } \\
\text { enjoyment? }\end{array}$ & $\begin{array}{l}\text { Compensation elicits higher } \\
\text { enjoyment than punishment. }\end{array}$ & Yes \\
\hline & \multirow[t]{2}{*}{$\begin{array}{l}\text { Q5 (a priori): Does time affect } \\
\text { enjoyment of punishment and } \\
\text { compensation? }\end{array}$} & $\begin{array}{l}\text { Punishment enjoyment } \\
\text { decreases over time (no } \\
\text { enjoyment by the end of the } \\
\text { experiment). }\end{array}$ & Partly \\
\hline & & $\begin{array}{l}\text { No prediction on the } \\
\text { temporal pattern of } \\
\text { compensation enjoyment. }\end{array}$ & NA \\
\hline \multirow[t]{3}{*}{$\begin{array}{l}\text { Punishment Motives } \\
\text { and Justifications: } \\
\text { Deterrence and } \\
\text { Retribution }\end{array}$} & $\begin{array}{l}\text { Q6 (a priori): Does framing } \\
\text { condition affect punishment } \\
\text { severity (during justice } \\
\text { administration)? }\end{array}$ & $\begin{array}{l}\text { The punishment frame most } \\
\text { in line with children's pre- } \\
\text { existing punishment } \\
\text { motivation increases } \\
\text { punishment severity. }\end{array}$ & No \\
\hline & $\begin{array}{l}\text { Q7 (a priori): Does children's age } \\
\text { affect retribution vs. deterrence } \\
\text { endorsement? }\end{array}$ & $\begin{array}{l}\text { Endorsement of deterrence } \\
\text { over retribution increases } \\
\text { with increasing age. }\end{array}$ & No \\
\hline & $\begin{array}{l}\text { Q8 (post-hoc): Does framing } \\
\text { condition affect frame } \\
\text { reproduction? }\end{array}$ & $\begin{array}{l}\text { Exploratory analyses, no } \\
\text { predictions. }\end{array}$ & NA \\
\hline
\end{tabular}

The study was approved by the XX University Ethical Review Committee under the 323 project name "Children's social judgement in a computer game” (Study Number X). All raw 324 data, experimental scripts, and analysis pipelines are available at the Open Science Framework 325 (https://osf.io/4ygw5/).

\section{Participants}

Exclusions from the dataset amounted to 3 children: 1 child was excluded because of an experimenter's technical mistake; 2 children had difficulties in comprehending experimenter's - S1). After exclusions participants were 123 children (mean age: 9.83 years; $S D=1.41$ years; 
332 year-olds, 23 10-year-olds, 34 11-year-olds; gender: 32 girls and 91 boys) residing in the UK (n

$333=67)$, Colombia $(n=23)$ or Italy $(n=33)$. Of these 123 children, 43 were assigned to the

334 retribution frame, 40 to the deterrence frame and 40 to the compensation frame (see

335 Supplemental Material - Table S3 for sample breakdown according to age, country and framing

336 condition). Our choice of countries was opportunistic to maximise diversity in the sample.

337 Sample size was determined by logistic constraints: we collected as much data as practically 338 possible within time-periods.

339 Participants were tested in one of two alternative settings: either face-to-face (at science 340 fairs or a technology-themed summer camp) or remotely over the internet (via Skype or 341 WhatsApp video or voice calls, depending on the reliability of the internet connection 342 participants had access to from their homes). Data collection lasted from late June 2018 to the 343 beginning of March 2019.

344 The Italian sample, consisting of 33 children mainly from middle-income backgrounds, 345 was tested entirely over the internet (nationwide recruitment). The Colombian sample, formed by 34623 children mainly from middle-to-high-income backgrounds, all recruited at the same summer 347 camp of a large city, was tested entirely in a face-to-face setting. The British sample, coming 348 from a mixed socio-demographic background, was the only one to be tested in both settings: 35 349 children over the internet (nationwide recruitment) and 32 face-to-face (recruitment at two 350 different science fairs in the same medium-sized English city). The categorisation of the children 351 in terms of their socio-economic status was made through informal communications with 352 gatekeepers or knowledge of general characteristics of the catchment areas.

\section{Stimuli}


354 Eight short videos depicting players' behaviours in Minecraft were recorded and 355 embedded into a Qualtrics platform questionnaire to create an online Justice System, called 356 Squidcraft (link to the Justice System Qualtrics: http://bit.ly/obust33 where video streaming has 357 now been disabled; videos now available at the Open Science Framework: https://osf.io/4ygw5/). 358 An offline version that was identical except for minor formatting aspects was also developed for 359 the purpose of testing at science fairs where the internet connection was not reliable. The system 360 was formatted to resemble an administrative control-panel interface rather than a questionnaire 361 (Figure 1).

The videos, varying in length from 25 to 54 seconds, represented various moral 363 transgressions during Minecraft play (see Table 2 for brief transgression descriptions and 364 Supplemental Material - S1.6 for full descriptions). 


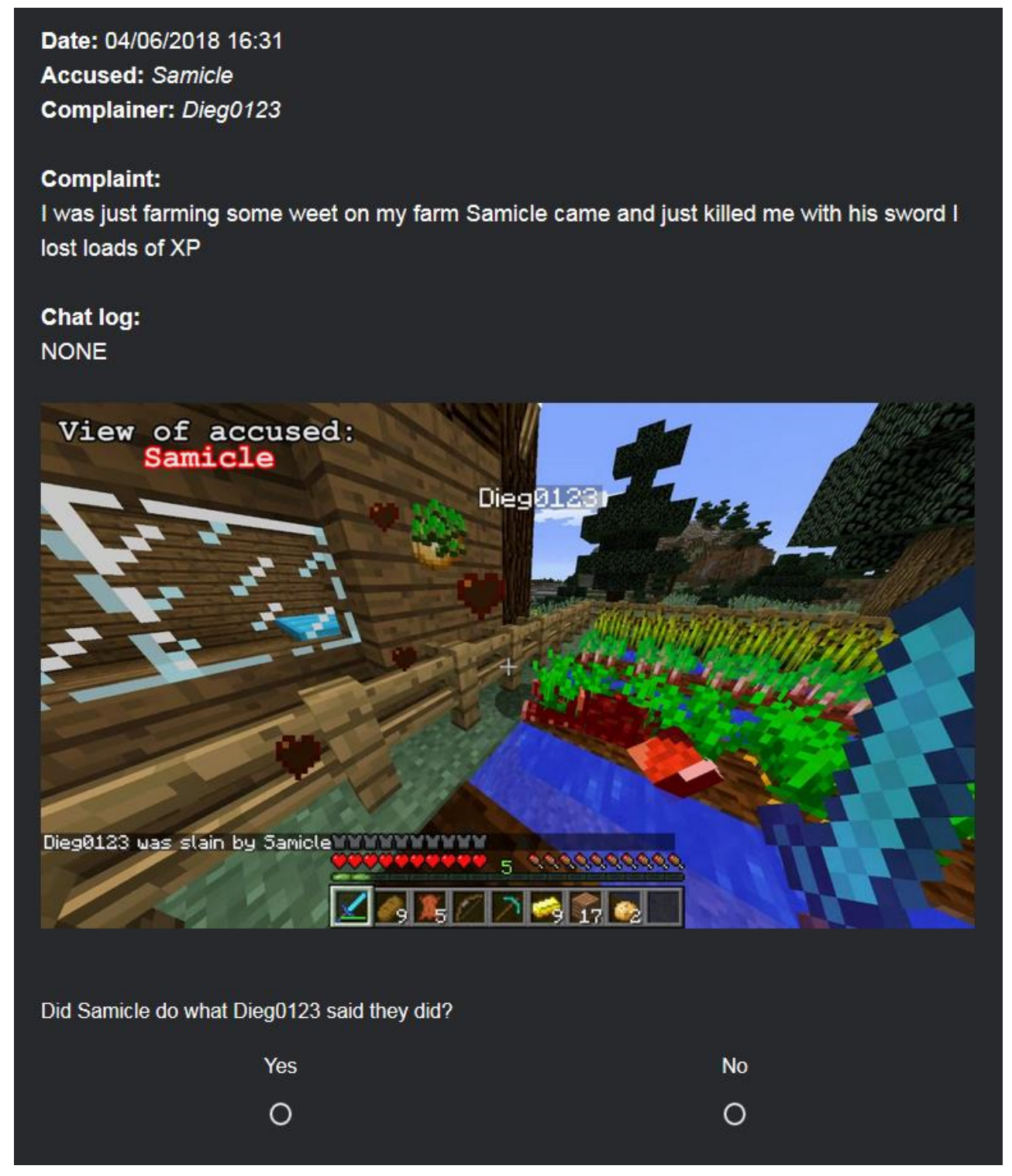

Figure 1. Screenshot from the Squidcraft Justice System interface operated by participants. Above: a still image from the Physical Harm condition video in which Samicle has just attacked and killed Dieg0123, and showing the first question to be answered.

\section{Design}

We adopted a mixed design in which the within-subject variables were time (during and

372 after justice administration) and transgression type (see Table 2 and Supplemental Material -

373 S1.6). The between-subject variables were country of residence (UK; Colombia; Italy); setting

374 method (over the internet; face-to-face); framing condition (retribution; deterrence; 
375 compensation); gender (male; female); and age (between 7 and 11 years of age). These between-

376 subject variables were counterbalanced against two between-subject nuisance variables:

377 transgression order (see Supplemental Material - Table S2) and question order (see

378 Supplemental Material - S1.8, S1.9, S1.10).

379 Table 2. Brief description of transgressions

\begin{tabular}{|c|c|}
\hline Transgression type & Description \\
\hline Physical harm & $\begin{array}{l}\text { Player } \mathrm{C} \text { was farming some wheat when he was unexpectedly killed by player A with a } \\
\text { sword. }\end{array}$ \\
\hline Property destruction & $\begin{array}{l}\text { Player } \mathrm{A} \text { and player } \mathrm{C} \text { worked together to build a house, but then player A destroyed it } \\
\text { by setting it on fire. }\end{array}$ \\
\hline $\begin{array}{l}\text { Sanctity/authority } \\
\text { transgression }\end{array}$ & $\begin{array}{l}\text { Player A killed a holy squid in a temple while player } \mathrm{C} \text { was making an offer of gold to } \\
\text { it. }\end{array}$ \\
\hline Theft & $\begin{array}{l}\text { While player } \mathrm{C} \text { and another player were trading an enchanted pick for an emerald, } \\
\text { player A appeared and stole both resources. }\end{array}$ \\
\hline Inequity/disloyalty & $\begin{array}{l}\text { Two players mining together (player A and player C) had promised each other to } \\
\text { equally divide any emeralds or diamonds they discovered. When they found two } \\
\text { emeralds, player A seized them both, refusing to share with player C. }\end{array}$ \\
\hline $\begin{array}{l}\text { Deception/liberty } \\
\text { violation }\end{array}$ & $\begin{array}{l}\text { Player A persuaded player } \mathrm{C} \text { to follow him into a place, where player A trapped player } \\
\mathrm{C} \text { inside an obsidian pit. }\end{array}$ \\
\hline $\begin{array}{l}\text { Harm-related false } \\
\text { accusation (control) }\end{array}$ & $\begin{array}{l}\text { Player C complained that she was set on fire by player } \mathrm{A} \text {, but the video reveals that this } \\
\text { was not the case. }\end{array}$ \\
\hline $\begin{array}{l}\text { Property-related trivial } \\
\text { accusation (control) }\end{array}$ & $\begin{array}{l}\text { Player C, who claimed to need a lot of wood, complained that player A had harvested a } \\
\text { tree in the village common forest. }\end{array}$ \\
\hline
\end{tabular}

Note: player A stands for "accused", while player C stands for "complainer". Children were asked to decide whether to punish the former and compensate the latter in the Squidcraft Justice System.

The dependent variables were punishment severity; compensation level; punishment enjoyment; compensation enjoyment; punishment vs. compensation endorsement; retribution vs. deterrence endorsement; frame reproduction and believability of the Justice System. Dependent variables were measured during justice administration (i.e., repeatedly after each moral transgression), after justice administration (i.e., after all moral transgression scenarios were complete), or at both time points (see Table 3 for details). After each moral transgression we also 
measured for use as a covariate the participant's judgement of transgression severity (on a 6-

point ordinal scale ranging from -5 , "very bad", to 0 , "not bad not good").

Table 3. Description of all dependent variables.

\begin{tabular}{|c|c|c|}
\hline Dependent variable & Time of measurement & Measurement scale \\
\hline $\begin{array}{l}\text { Frame reproduction } \\
\text { (manipulation check) }\end{array}$ & $\begin{array}{l}\text { Before Trial 1; between } \\
\text { Trials 4-5 }\end{array}$ & $\begin{array}{l}\text { Categorical choices: "punishment with undetermined } \\
\text { motivation"; "retribution"; "deterrence"; "compensation" }\end{array}$ \\
\hline Punishment severity & $\begin{array}{l}\text { During justice } \\
\text { administration }\end{array}$ & $\begin{array}{l}\text { 11-point ordinal scale, ranging from } 0=\text { "no ban from the } \\
\text { server" to } 10=\text { " } 4 \text { week-ban" }\end{array}$ \\
\hline Compensation level & $\begin{array}{l}\text { During justice } \\
\text { administration }\end{array}$ & $\begin{array}{l}\text { 11-point ordinal scale, ranging from } 0=" 0 \text { Minecraft } \\
\text { diamonds" to } 10=\text { " } 10 \text { Minecraft diamonds" }\end{array}$ \\
\hline Punishment enjoyment & $\begin{array}{l}\text { During and after justice } \\
\text { administration }\end{array}$ & $\begin{array}{l}\text { 11-point ordinal scale: }-5 \text { was "very bad"; } 0 \text { was "not bad } \\
\text { not good"; }+5 \text { was "very good" }\end{array}$ \\
\hline Compensation enjoyment & $\begin{array}{l}\text { During and after justice } \\
\text { administration }\end{array}$ & $\begin{array}{l}\text { 11-point ordinal scale: }-5 \text { was "very bad"; } 0 \text { was "not bad } \\
\text { not good"; }+5 \text { was "very good" }\end{array}$ \\
\hline $\begin{array}{l}\text { Punishment vs. } \\
\text { compensation } \\
\text { endorsement }\end{array}$ & $\begin{array}{l}\text { During and after justice } \\
\text { administration }\end{array}$ & $\begin{array}{l}\text { Binary choice between } 0=\text { "compensation" and } 1= \\
\text { "punishment" }\end{array}$ \\
\hline $\begin{array}{l}\text { Retribution vs. } \\
\text { deterrence endorsement }\end{array}$ & $\begin{array}{l}\text { After justice } \\
\text { administration }\end{array}$ & $\begin{array}{l}\text { Binary choice between } 0=\text { "deterrence" and } 1= \\
\text { "retribution" }\end{array}$ \\
\hline $\begin{array}{l}\text { Believability of the } \\
\text { Justice System } \\
\text { (manipulation check) }\end{array}$ & $\begin{array}{l}\text { After justice } \\
\text { administration }\end{array}$ & $\begin{array}{l}\text { Binary choice between } 0=\text { "not believable" and } 1= \\
\text { "believable" }\end{array}$ \\
\hline
\end{tabular}

\section{Procedure}

Parents gave consent for their children to participate after having received information about the experiment; an opt-in consent system was applied in Italy and the UK, opt-out consent in Colombia (as usage of Minecraft was already part of the standard activities of the summer camp we recruited from). In addition to a specific age range (7-11 years), the other requirement understand the dynamics between the players (experience with Minecraft was certified by the children's parents). 
After establishing the connection (for internet data collection) or seating the child at the

402

403

404

405

406

407

408

409

410

411

412

413

414

415

416

417

418

419

420

421

422

423

computer (for face-to-face data collection), the procedure began with the researcher explaining that during the experiment they would not be Minecraft players themselves but rather judges helping to test a newly set up Justice System for a Minecraft server called Squidcraft (a Minecraft server is an online multiplayer arena where players can interact in numerous ways, with some servers allowing both prosocial and antisocial interactions - the latter is known informally as "griefing"; Beale et al., 2016). Participants were told that players on the server experiencing misbehaviours from other players could log their complaints into the Justice System. These complaints along with the chat logs between the players and video renditions of the behaviour in question (see Supplemental Material - S1.6 for details of the complaints and chat logs) would then be shown to a Justice System judge for action to be taken (very similar player-operated justice systems feature in real computer games, e.g., Kou et al., 2017). In reality the complaints and chat logs had been previously written, as well as the videos pre-recorded. This element of deception was revealed to the children once the experiment was completed.

According to the framing condition children were assigned to, the purpose of the Justice System was described by either emphasising its retributive or deterrent or compensatory functions. This frame was repeated twice, paraphrased in different ways (see Supplemental Material - S1.2 and S1.4). The experimenter checked twice whether children could reproduce (with their own words) the frame: before Trial 1 (immediately after framing), and then again between Trials 4 and 5. In both frame manipulation checks, children were asked if they remembered the purpose of the Justice System. The experimenter immediately coded whether their explanations contained mentions of compensation, deterrence, retribution or of a general punitive motivation with no specific links to retribution or deterrence. When children's answers 
424 did not match the assigned frame, the experimenter repeated the frame to them. Recordings were 425 blind double-coded (see Supplemental Material - S4.1 for coding criteria).

After children had responded to the first frame manipulation check, the experimenter 427 assisted them to navigate to the first complaint of the Justice System (for example, for internet 428 data collection, by pasting the link into the text-chat channel of the connection), thus starting the 429 justice administration phase of the experiment. Following the reading of the relevant chat log and 430 the viewing of the video, children were asked if they believed the accused player had done what 431 the complaining player said they did. In case of an affirmative answer, children were required to 432 judge the accused player's transgression by rating its severity on a scale ranging from "very bad" 433 to "not bad not good" (first 6 points of the Likert scale in Figure 2). At this point, children could 434 decide both the amount of compensation (number of diamonds) to allocate to the 435 complainer/victim and the amount of punishment (length of ban from the server) for the 436 accused/transgressor. Children did not have to pay any economic cost to enact their third-party 437 decisions; however, the consequences of these decisions for transgressors and victims were 438 presented as real, and the children used the Justice System interface to make the decisions. In 439 order to avoid ceiling effects with compensation choices, the experimenter initially specified that 440 diamonds were limited and discouraged the children from always giving the maximum number 441 of diamonds. The order of punishment and compensation-related questions was counterbalanced 442 across participants.

443 Immediately after children decided to enact punishment and/or compensation (i.e., during 444 justice administration), they were asked to indicate how they felt in punishing and/or 445 compensating on a scale ranging from "very bad" to "very good" (all 11 points of the Likert 446 scale in Figure 2). The enjoyment question during justice administration was asked multiple 
447 times (i.e., every time children had punished a moral transgression). If children had decided to

448 assign both punishment and compensation, they answered a forced-choice question about

449 whether they considered the former or the latter (with order of mentioning counterbalanced)

450 more important in this specific case.

451 All participants were presented with the same 8 complaints with order of appearance

452 counterbalanced across participants. When all the 8 complaints had been judged (i.e., after

453 justice administration), participants had to answer the final block of questions. Children had to

454 rate on the 11-point Likert scale how performing acts of punishment and compensation had made

455 them feel; whether they attributed more importance to punishing transgressors or compensating

456 victims; and whether their main reason for punishing transgressors was for deterrence or

457 retribution. The internal order of these questions was counterbalanced across participants.

458 Finally, the experimenter checked whether children truly believed they had judged

459 misbehaviours that had actually happened on the Minecraft server (see Supplemental Material -

460 S1.10 for details of the questions). Of note, self-reported measures (particularly endorsement of

461 punishment vs. compensation, and of retribution vs. deterrence) were asked after the behavioural

462 measures (punishment severity and compensation level). We consider this arrangement best

463 suited to minimise the risk that individual differences in endorsements influence children's

464 behavioural choices downstream.

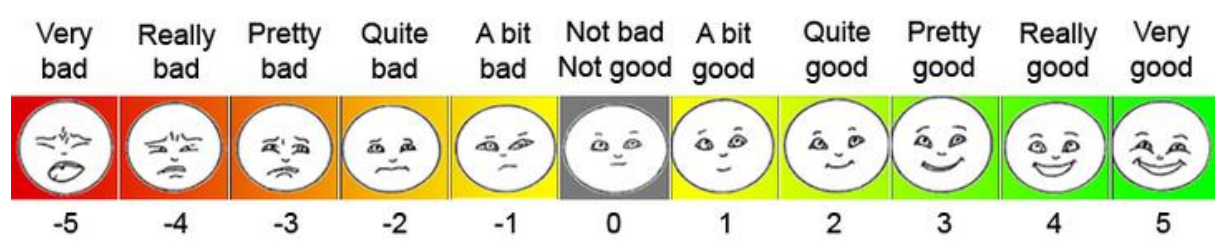

Figure 2. Likert scale used to measure both judgements of transgression severity and the 467 affective states related to punishment and compensation. 
To test our research hypotheses, we adopted linear models implemented using the lme4

471 package (Version 1.1-26) in the $\mathrm{R}$ programming environment (Version 4.0.2, R Core Team, 472 2020). We used lmer to analyse linear mixed-effects models of continuous dependent variables 473 (punishment severity, punishment enjoyment, compensation level, compensation enjoyment); 474 glmer to analyse logistic mixed-effects models of binary dependent variables (punishment vs. 475 compensation endorsement during justice administration); and $g \operatorname{lm}$ to analyse linear fixed-effects 476 models of binary dependent variables (retribution vs. deterrence endorsement, punishment vs. 477 compensation endorsement after justice administration). To test predictions and to explain variance in dependent variables (and thus increase 479 statistical power to test predictions) models included a range of factors (fixed unless stated 480 otherwise). All models included age, framing condition, setting method, gender, country of 481 residence, question order, and believability (to test predictions and explain variance). All within482 subject models include participant ID as a random factor. When dependent variables were 483 modelled trial-by-trial during justice administration, models included transgression severity 484 judgement and transgression type (to test predictions and explain variance), with transgression 485 type as a random factor to improve generalisability of findings. When dependent variables were 486 modelled to compare their values during and after justice administration, the model compares the 487 mean dependent-variable value during justice administration trials with the value from 488 afterwards, and models included time-point (during vs. after, to test predictions) and mean 489 transgression severity judgement during trials (to explain variance). Regarding the nuisance 490 variables, only question order and not transgression order was included because of stronger 491 theoretical reasons to expect an effect (Condon \& DeSteno, 2011). Because of the large number 
492 of relations between variables included in these models, we discuss in main text only relations

493 for which we made predictions, to minimise the false discovery rate. In all our models we

494 included only main effects, not interaction effects. For intuitive interpretation, some effect sizes

495 for pair-wise category comparisons are stated as Cohen's $d$ with associated confidence interval

496 (CI); these are calculated by dividing the relevant dummy regression coefficient and associated

497 CI by the standard deviation of the dependent variable. See tables S4 to S11 for full model 498 specifications.

499 Preliminary analysis of the control scenarios revealed that for the false accusation, none

500 of the participants identified the accused as having done something wrong, and in the trivial 501 accusation, children barely expressed any negative judgement (see Supplemental Material 502 S3.1). Analyses presented below therefore exclude the two control scenarios, which served their 503 purpose by demonstrating that participants could distinguish substantive accusations from false 504 or trivial accusations.

\section{Results}

\section{Method Validation: Setting Method and Believability}

The setting method did not have any effect on any of the key dependent variables: all ps

$508>.100$ (see Supplementary Materials, Tables S4-S11), suggesting no important differences 509 between conducting the experiment remotely over the internet and face-to-face. In total $88 \%$ $510(95 \%$ CI $[82 \%, 94 \%])$ of children believed the events shown had actually happened on the 511 SquidCraft server.

\section{Third-Party Interventions: Compensation and Punishment}

Overall, during justice administration children expressed preferences for punishment: in

$51457 \%(95 \%$ CI $[53 \%, 61 \%])$ of the test trials children endorsed punishment over compensation 
515 when asked to choose. Moreover, punishment vs. compensation endorsement during justice 516 administration was not affected by children's age $\chi^{2}(1)=2.68, p=.102, \Delta \mathrm{R}^{2}=.006, \mathrm{OR}=1.16$, $51795 \%$ CI $[0.97,1.35]$ (Q3, Table 1; see Table S6 for the full model for this variable). In contrast, 518 judgement of transgression severity was a significant predictor, $\chi^{2}(1)=4.50, p=.034, \Delta \mathrm{R}^{2}=$ 519.008 (Q1, Table 1). Specifically, the more severely children judged the transgressions, the more 520 likely they were to endorse punishment over compensation, OR $=0.85,95 \%$ CI $[0.73,0.98]$.

521 Transgression type was also a significant predictor, $\chi^{2}(1)=10.73, p=.001, \Delta \mathrm{R}^{2}=.032(\mathrm{Q} 2$, 522 Table 1).

523 Most transgression types did not elicit preferential endorsement either of punishment or 524 of compensation - the two exceptions for which punishment was clearly the favourite option 525 were for transgressions related to sanctity/authority and liberty/deception (Figure 3). There were 526 no transgression types eliciting a preference for compensation. The significant effect of 527 transgression type is explicable with reference to the observation that theft elicited lower 528 endorsement of punishment over compensation than what would be expected from the judgement 529 of the severity of this transgression (Figure 3).

530 After justice administration children's preferences for punishment were confirmed: $60 \%$ $531(95 \%$ CI $[51 \%, 68 \%])$ of children endorsed punishment over compensation in the forced-choice 532 task. This was affected by age, $\chi^{2}(1)=7.59, p=.006, \Delta \mathrm{R}^{2}=.072(\mathrm{Q} 3$, Table 1 ; see Table S7 for 533 the full model for this variable): the older the children, the more likely they were to endorse 534 punishment over compensation, $\mathrm{OR}=1.58,95 \% \mathrm{CI}[1.14,2.25]$. 


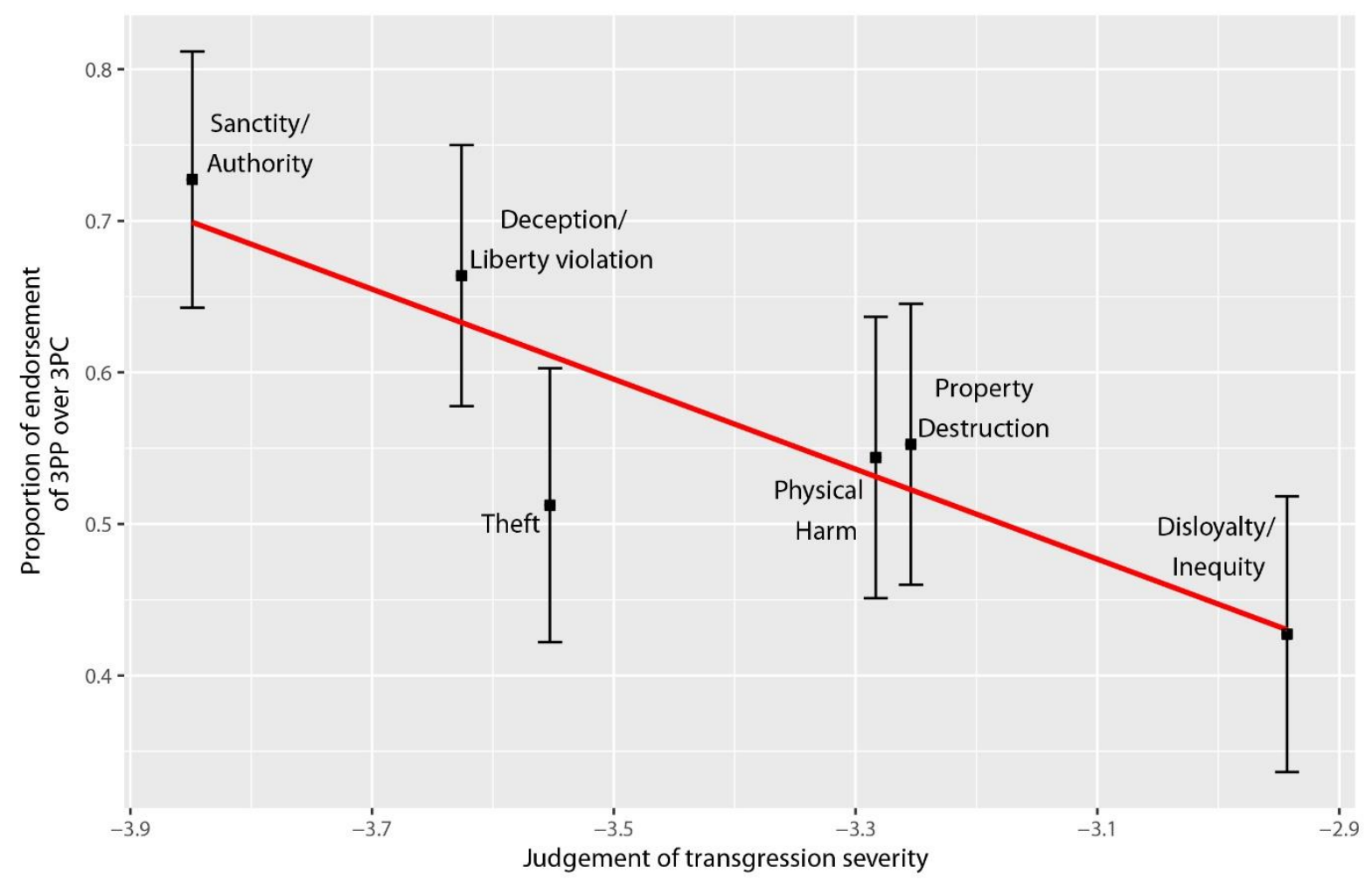

Figure 3. Proportion of endorsement of punishment over compensation in relation to judgement of transgression severity across transgression types. 3PP: punishment; 3PC: compensation. In judgement of transgression severity, more negative numbers indicate more severe judgements. 95\% CIs are shown for each transgression type; the regression line is based on the proportions for each transgression type.

541

\section{Affective States Induced by Third-Party Interventions}

Children's enjoyment was predicted by type of third-party intervention, $\chi^{2}(1)=76.38, p$ more enjoyment $(M=3.31, S D=1.34)$ than punishment $(M=2.27, S D=1.96), d=0.61,95 \%$ when measured after justice administration $(M=2.04, S D=2.31)$ than when measured during justice administration $(M=2.50, S D=1.53), d=-0.24,95 \%$ CI $[-0.42,-0.07]$. 
551 (Q5, Table 1; see Table S10 for the full model), but the temporal pattern was different from

552 punishment enjoyment: compensation enjoyment was higher after justice administration $(M=$

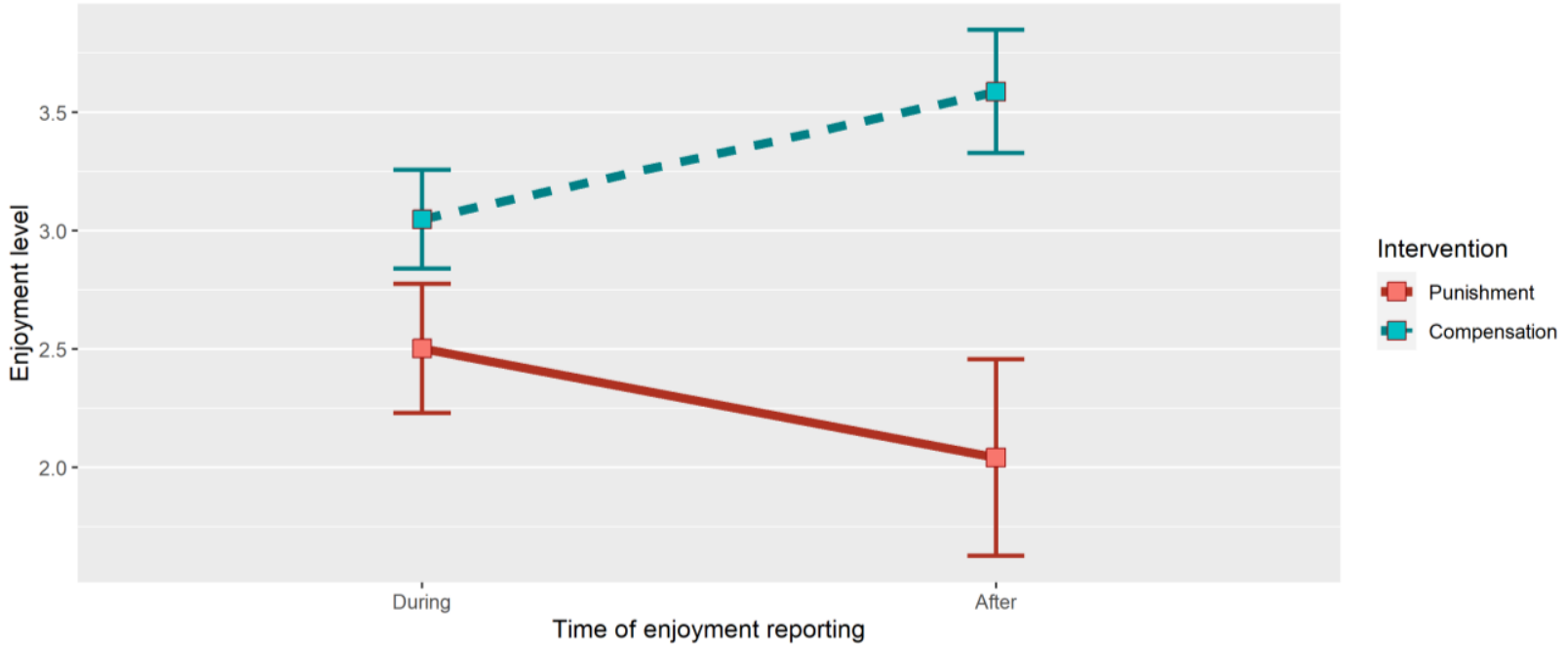

Figure 4. Enjoyment level reported at different time points for the two types of third-party 557 intervention. Error bars represent 95\% CIs of means. Note that enjoyment after justice 558 administration (one data point per individual) was compared with enjoyment during justice administration (data points averaged over each individual's six test trials).

\section{Punishment Motives and Justifications: Deterrence and Retribution}

During justice administration, punishment severity did not change across framing conditions, $\chi^{2}(1)=2.26, p=.324, \Delta \mathrm{R}^{2}=.008$ (Q6, Table 1; see Table S4 for the full model for

564 this variable). For the important retribution vs. deterrence comparison, $d=0.16,95 \%$ CI [-0.12, 0.43] (a positive value means higher punishment severity in the deterrence frame), indicating the

566 possibility of a small undetected effect. After justice administration, 88\% (95\% CI [80\%, 93\%]) of children endorsed deterrence over retribution in the forced-choice task. This overwhelming 
568 endorsement of deterrence did not vary as a function of age, $\chi^{2}(1)=0.18, p=.668, \Delta \mathrm{R}^{2}=.002$, 569 OR $=0.91,95 \%$ CI $[0.57,1.43]$ (Q7, Table 1; see Table S11 for the full model for this variable). 570 Given the lack of framing effects on punishment severity (as well as on all other key 571 variables), we examined if there were framing effects on children's answers to the framing 572 manipulation checks (Q8, Table 1), which assessed children's understanding of the Justice 573 System's presented purpose (a post-hoc investigation). Children's mentions of retribution, 574 deterrence and compensation significantly varied across framing conditions (all $p s \leq .001$ at 575 Checks 1-2, Fisher's exact tests; Figure 5), indicating that the framing manipulation did affect 576 children's understanding of the Justice System's purpose. Specifically, mentions of retribution 577 were more common in the retribution condition than in the compensation condition (Checks 1-2, $578 p s<.010)$ and deterrence condition (Checks 1-2, ps<.050). Mentions of deterrence were more 579 common in the deterrence condition than in the compensation condition (Checks 1-2, ps $<.001$ ) 580 and retribution condition (Checks 1-2, ps<.050). Mentions of compensation were more 581 common in the compensation condition than in the deterrence condition (Checks 1-2, ps $<.001$ ) 582 and retribution condition (Checks 1-2, ps $<.010)$.

583 A salient observation is that deterrence was more commonly mentioned than retribution 584 (in line with the results for deterrence vs. retribution endorsement after justice administration). 585 For example, retribution was almost never mentioned by participants in the deterrence frame 586 condition, whereas deterrence was mentioned as often as retribution by participants in the 587 retribution frame condition (Figure 5). Inter-coder reliability was good with regards to the 588 proportion of children mentioning each motivation (Supplemental Material - S4.4). 
601 punishment.

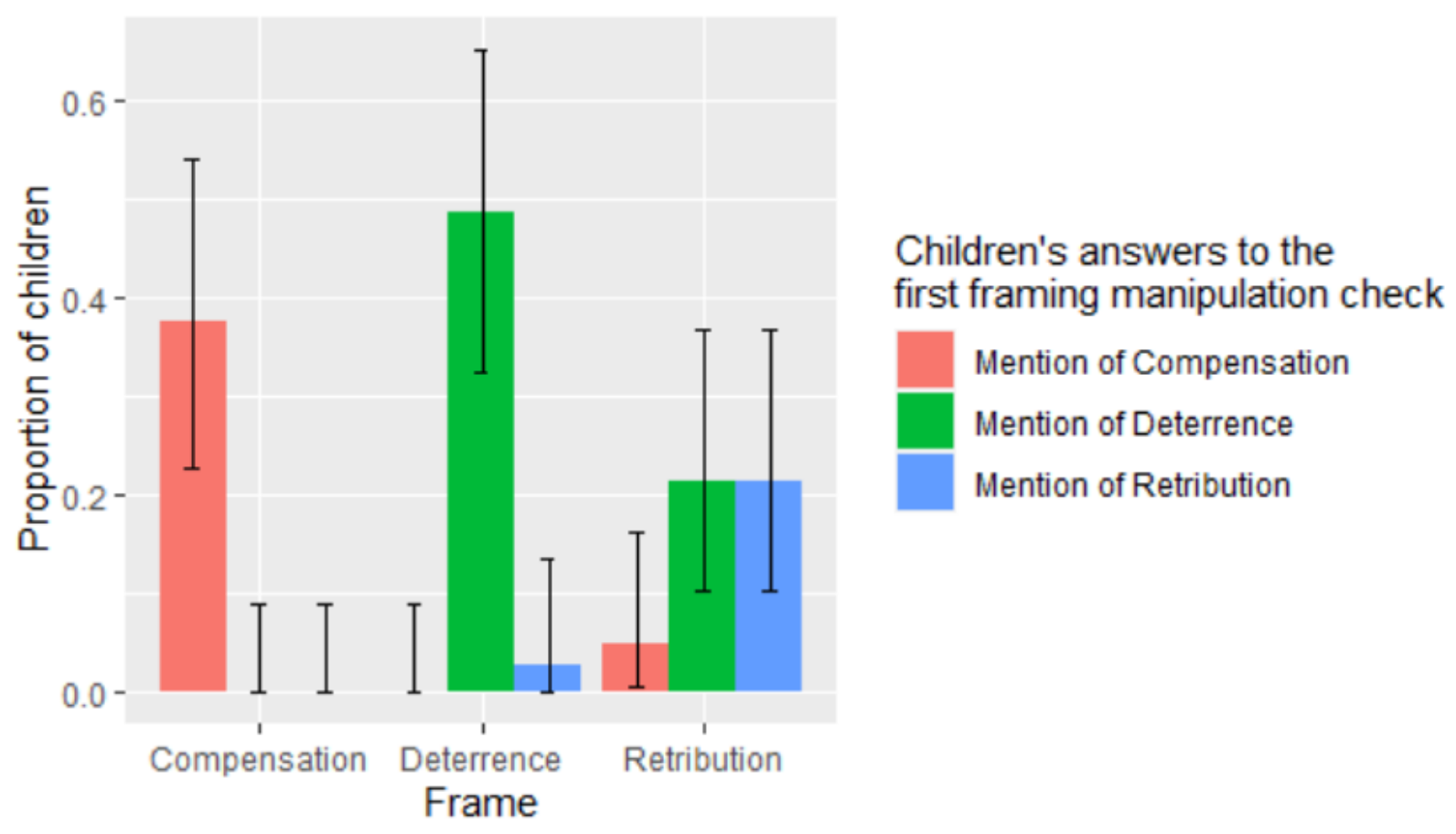

Figure 5. Proportion of children who mention compensation, deterrence and retribution across framing conditions at the first framing manipulation check (responses at the second manipulation check were very similar, see Supplemental Material - Figure S2). Error bars represent $95 \%$ CIs of proportions.

\section{Discussion}

Our research advanced knowledge about important but relatively un-investigated topics in developmental psychology: the modulating factors of children's orientation for punishment or compensation; the emotional consequences of enacting punishment and compensation; and the justifications and motives (deterrence vs. retribution) behind children's decisions to inflict Interestingly, high levels of endorsement of deterrence over retribution were found, irrespective of children's age, confirming that it is normal for children (as well as adults) to conceive of punishment as being for deterrence (Yudkin et al., 2019; Stern \& Peterson, 1999; Bregant et al., 2016; Dunlea \& Heiphetz, 2021; Marshall et al., 2022). However, since children, 
606 relative to adults, have less developed inhibitory control and forward-looking reasoning skills, it

607 seems less likely that their high levels of deterrence endorsement result from sophisticated

608 deliberative processes (as discussed by Bregant et al., 2016). The observed tendency of children

609 to default to deterrence-based explanations of punishment raises the possibility that deterrence

610 reasoning is more intuitive, which would contravene some assumptions in the adult literature

611 (Aharoni \& Fridlund, 2012; Keller et al., 2010; Carlsmith \& Darley, 2008; but see Rehren \&

612 Zisman, 2022). However, this should be tested with younger children than those in our sample.

613 Moreover, contrary to our predictions, whether the punishment frame was deterrence or

614 retribution had no effect on children's punishment severity. This suggests that, in this context,

615 children tend to act according to their preconceived notions of what is right, not merely what

616 they are told should be done. Importantly, we can rule out that these null effects are due to the

617 total ineffectiveness of our framing manipulation: we did observe framing effects in the

618 manipulation check. The frequency of children's mentions of retribution, deterrence, and

619 compensation depended on the framing condition, indicating that children tended to remember

620 the experimenter's framing explanations; they did not purely report their pre-existing justice

621 beliefs. However, a further salient result from the manipulation checks was that children

622 assigned to punishment frames were biased towards explaining the Justice System in terms of

623 deterrence, showing that the preference for deterrence over retribution evident in the forced-

624 choice endorsement task generalised to this open-ended measure. These results are also in line

625 with previous work showing that children are sensitive to deterrence cues (Marshall et al., 2021;

626 Twardawski \& Hilbig, 2020). We note further that our between-subjects statistical power was

627 lower than ideal, and the confidence interval for the size of the effect on punishment severity of 
628 deterrence vs. retribution frames allows for a small undetected effect: children might punish 629 slightly more given a deterrence frame in this context.

630 It is possible that explaining the experiment to children as a Justice System where they 631 would take the role of judges affected our results (Gonzalez-Gadea et al., 2022): this may have 632 geared children toward remembering and endorsing more deterrence-based explanations for 633 punishment. However, it has also been demonstrated that children explain punishment in terms 634 of deterrence irrespective of social roles, as they overwhelmingly attribute deterrent motives to 635 institutional and peer punishers alike (Marshall et al., 2022). It remains to be clarified whether 636 children's endorsement of deterrence in our experiment was due to the high frequency at which 637 children in everyday life are familiarised with pedagogical uses of punishment (Marshall et al., 638 2022), an experience that would promote internalisation of deterrent messages.

639 With respect to children's affective states related to third-party interventions, it was 640 found that compensation elicited more enjoyment than punishment, as predicted. This could be 641 due to a "warm glow" effect deriving from the experience of giving to people in need (Andreoni, 642 1990). From an early age children show sympathetic behaviour towards victims of transgressions 643 (Vaish, et al., 2009) and are motivated to see others get the help they need (Hepach et al., 2016). 644 Moreover, both compensation and punishment enjoyment were time-dependent but followed 645 different temporal patterns: compensation enjoyment increased, while punishment enjoyment 646 declined over time. The decrease in punishment enjoyment is unlikely to be due to emotional 647 memory extinction (LaBar \& Cabeza, 2006) because the same process would probably have 648 governed compensation enjoyment too, which instead showed an increase over time. Whereas 649 the temporal pattern of compensation enjoyment might be indicative of children's positive 650 reappraisal of the impact of their action on the victims, the temporal pattern of punishment 
651 enjoyment is in accordance with Carlsmith et al.'s (2008) finding that enacting punishment

652 causes rumination and thus lowering of mood. It is also possible that the decrease of punishment

653 enjoyment over time might also indicate that children experienced a social desirability bias to

654 show regret.

655 Children enjoyed compensating victims more than punishing transgressors, yet they

656 preferentially endorsed punishment over compensation (after justice administration, and with

657 increasing judgement severity during justice administration). This misalignment between

658 affective states and endorsements suggests that children see punishment as a duty to fulfil even if

659 unpleasant. This sense of duty might arise in part because of demand characteristics of the

660 situation (being repeatedly asked to contemplate allocated punishment and compensation), but

661 this does not explain the mismatch between affective states and endorsement. Whether this duty

662 is about meeting retributive (i.e., transgressors' suffering) or deterrent goals (i.e., transgressors

663 learning their lesson) is difficult to establish from our affective results, since previous literature

664 demonstrated that both are linked to higher punishers' satisfaction (Aharoni et al., 2022).

665 However, a retributive explanation for children's punishment seems unlikely given our findings

666 that children overwhelmingly endorsed deterrence irrespective of age and had a recollection of

667 the purpose of the Justice System biased towards deterrence.

668 Children's punishment-related affective states were positive, albeit not as positive as

669 compensation-related affective states. This finding is thus in contrast with a previous study that

670 found children usually did not enjoy enacting their punishment decisions (Arini et al., 2021). The

671 specificities of the different experiments might account for these contrasting results. In the

672 paradigm used by Arini et al. (2021) the allocation of punishment to the transgressor was more

673 visually and auditorily salient for the participant than in the Minecraft paradigm, which might 
674 have elicited a sense of compassion for the punished transgressor. Moreover, in Arini et al.'s 675 (2021) experiments children did not have previous experience with the game, whereas 676 participants in the Minecraft experiment were familiar with Minecraft and generally enjoy 677 playing and thinking about it. Most importantly, in Arini et al.'s (2021) paradigm children could 678 only assign punishment, while in the Minecraft paradigm they could both punish transgressors 679 and compensate victims, thus contributing to a greater overall sense of justice being restored.

As expected, the seriousness of a transgression influenced children's third-party 681 interventions. Analyses showed that children preferred to endorse punishment over 682 compensation during justice administration when they judged transgressions more severely. 683 Furthermore, children's endorsement of punishment vs. compensation during justice 684 administration was affected by transgression type. Contrary to our predictions, children did not 685 preferentially endorse punishment in cases of harm violation (Miller \& McCann, 1979), and 686 compensation in cases of theft (Riedl et al., 2015; Yang et al., 2021; Liu et al, 2021) and inequity 687 (Lee \& Warneken, 2020). Transgressions in sanctity/authority and liberty/deception were in fact 688 the only contexts eliciting clear preferential endorsement of punishment: for the majority of 689 transgression types children did not express preferential endorsement either of punishment or of 690 compensation during justice administration.

691 To note, the sanctity/authority transgression (i.e., killing a squid, usually allowed but not 692 on this particular Minecraft server because of their status of holy animal) was the scenario 693 prompting the highest rates of punishment endorsement. Whereas all the other moral norms such 694 as killing players and stealing were independent of this Minecraft server, this norm was novel 695 and unique. This may relate to the particular importance of sacred ingroup values (Tetlock, 696 2003), and is telling of the malleable nature of children's norm learning (Rakoczy et al., 2008) 
697 and of the volatility of moral norms on the internet. This may also speak to the strong potential 698 for information associated with religious contexts to be quickly accepted by children (Vaden \& 699 Woolley, 2011).

Interestingly, theft elicited higher endorsement of compensation over punishment than expected on the basis of judgement of transgression severity. To explain this result, we refer to 702 the evidence that children use punishment as an opportunity to directly right the wrong when it concerns resources (Arini et al., 2021). In the current experimental setting, punishment (i.e., 704 banning the transgressor from the game) was not suitable for equalising the resource unbalance 705 between victim and transgressor after a theft, so children reacted to this scenario by instead using 706 compensation (i.e., giving diamonds to the victim) to fulfil their equalisation purposes.

707 Whereas several transgression types did not cause preferential endorsement of 708 punishment over compensation during justice administration, a clear preference for endorsement 709 of punishment was observed after justice administration. This result could be because a generic 710 and abstract sense that moral transgressions have occurred in the past might elicit children's 711 intuitive reaction to endorse punishment. On the other hand, requiring children to attend in real 712 time to the details of the different transgression types might induce them to engage in careful 713 deliberation about whether it is more appropriate to endorse punishment or compensation (Van 714 Doorn \& Brouwers, 2017). The preferential endorsement of punishment after justice 715 administration is also indicative of children's transgressor-centred approach to justice 716 restoration. This is in accordance with the other behavioural studies in the developmental 717 literature in which punishment was preferred over compensation, when the latter was 718 operationalised as any prosocial actions towards the victim (McAuliffe \& Dunham, 2021), other 719 than restitution of previously subtracted resources (Riedl et al., 2015; Yang et al., 2021). This is 
720 also in accordance with the studies in the adult literature in which third-party interventions were

721 not costly to the participants (Adams \& Mullen, 2015; van Prooijen, 2010), as in our experiment.

722 In contrast, studies with adult participants providing evidence for preference for compensation

723 commonly employed paradigms where third-parties' economic resources were at stake (Chavez

724 \& Bicchieri, 2013; Lotz et al., 2011; Van Doorn, Zeelenberg, \& Breugelmans, 2018; Van Doorn,

725 Zeelenberg, Breugelmans, et al., 2018).

726

Finally, regarding the investigation of developmental patterns, as hypothesised on the

727 basis of the studies conducted by Riedl et al. (2015) and Miller \& McCann (1979), we observed a

728 developmental increase in the proportion of children endorsing punishment over compensation

729 after justice administration (a finding consistent with later studies by Yang et al., 2021 and

730 McAuliffe \& Dunham, 2021). This points to the possibility that, although children are willing to

731 punish transgressors from an early age (e.g., Kenward \& Östh, 2012, 2015), attitudes towards

732 this type of third-party intervention are further subject to learning processes. Because third-party

733 punishment is administered in schools and households, children may learn that punishment is a

734 socially approved choice (Marshall et al., 2022), and indeed there is evidence that young children

735 attribute reputational benefits to punishing (Vaish et al., 2016, although see Eriksson et al., 2016;

736 Raihani \& Bshary, 2015b; Dhaliwal et al., 2021 for opposite examples in adults).

737 Regarding the limitations of our study, as noted above, some effect-size confidence-

738 intervals reflect the possibility of undetected effects due to lower than ideal power, and further,

739 the samples of recruited children were not necessarily representative of the respective national

740 populations. Children tested face-to-face while attending science-themed fairs and summer

741 camps came from households characterised by higher education and socio-economic conditions

742 than the national average. In comparison, online testing was more able to reach children of 
743 diverse backgrounds. The internal cultural diversity of our sample is in some ways a strength, but

744 the relatively small sample from each country (in part due to greater difficulties with internet

745 recruiting than expected) also represents a weakness. We were unable to fully counterbalance the

746 setting method across different countries. Only British children were tested in both settings,

747 whereas Colombian children were tested exclusively face-to-face and Italian children exclusively

748 over the internet. Having said that, the statistical analyses we conducted always controlled for

749 children's country of residence and setting method, and our aim to test a broad range of children

750 in terms of nationalities was mainly motivated by the desire to maximise the chances of detecting

751 common patterns of moral behaviour rather than cross-cultural differences.

752 Future avenues for investigating children's third-party interventions should take

753 advantage of multiple methodologies. Qualitative and possibly longitudinal studies could provide

754 a more detailed insight into the development of children's concepts about punishment

755 justifications. From interviews with children and their parents and teachers, it would be also

756 possible to discern to what extent children's beliefs about punishment are affected by their

757 familiarity with deterrent justifications in the family and school setting (Sorbring et al., 2006).

758 Questionnaire studies could shed light on personality differences in children endorsing

759 punishment vs. compensation, and retribution vs. deterrence. Finally, experimental studies could

760 complement the picture by measuring children's affective states in three different conditions:

761 when they are given only the opportunity to enact punishment of transgressors; when they are

762 given only the opportunity to compensate victims; and when they can choose to either punish or 763 compensate.

Before concluding, we briefly address methodological implications. To our knowledge 765 this has been the first study in which developmental psychologists have tested children in a 
766 virtual environment (i.e., a Justice System) relating to an online game of their choice, by making

767 use of video chat and voice call applications. The lack of any differences in the key variables

768 depending on whether children were tested over the internet or face-to-face, and the high rates at

769 which children believed they were enacting interventions with real consequences for victims and

770 transgressors, together provide evidence that our innovative computer-mediated paradigm has

771 the potential to fundamentally change the practicalities of collecting some types of behavioural

772 data. However, care must be taken not to overgeneralise this result to different studies. Further,

773 whilst online testing is arguably more scalable than in-person testing, online recruitment of

774 children is not without its own specific set of challenges (e.g., parents might have lower trust in

775 researchers they have not met). Future studies should therefore systematically investigate

776 different online recruitment methods in order to identify the most effective ones.

\section{Conclusion}

We demonstrated that children overwhelmingly reported deterrence as their punishment justification, across a wide age range. Additionally, the more severely children judged the 780 transgressions, the more they endorsed punishment over compensation during justice 781 administration, revealing a transgressor-centred approach to justice restoration. Moreover, even 782 though children explicitly endorsed punishment over compensation after justice administration, they derived higher enjoyment from compensating victims than from punishing transgressors.

784 Finally, whereas compensation enjoyment increased, punishment enjoyment decreased over 785 time. Results from enjoyment, endorsement, and justification measures together suggest that 786 children enacting punishment behaviour are motivated by a sense they ought to punish to fulfil 787 social obligations and achieve deterrence. How children's punitive sentiment becomes more motivated by retribution, as it is in adults, is a question that awaits future investigation. 
Adams, G. S., \& Mullen, E. (2015). Punishing the perpetrator decreases compensation for victims. Social Psychological and Personality Science, 6(1), 31-38. https://doi.org/10.1177/1948550614542346

Aharoni, E., \& Fridlund, A. J. (2012). Punishment without reason: Isolating retribution in lay punishment of criminal offenders. Psychology, Public Policy, and Law, 18(4), 599. https://doi.org/10.1037/a0025821

Aharoni, E., Simpson, D., Nahmias, E., \& Gollwitzer, M. (2022). A painful message: Testing the effects of suffering and understanding on punishment judgments. Zeitschrift für Psychologie, 230(2), 138-151. https://doi.org/10.1027/2151-2604/a000460

Andreoni, J. (1990). Impure altruism and donations to public goods: A theory of warm-glow giving. The Economic Journal, 100(401), 464-477. https://doi.org/10.2307/2234133

Arini, R. L., Wiggs, L., \& Kenward, B. (2021). Moral duty and equalization concerns motivate children's third-party $\quad$ punishment. Developmental Psychology,57(8), 1325. https://doi.org/10.1037/dev0001191

Beale, M., McKittrick, M., \& Richards, D. (2016). “Good” grief: Subversion, praxis, and the unmasked ethics of griefing guides. Technical Communication Quarterly, 25(3), 191-201. https://doi.org/10.1080/10572252.2016.1185160

Bentham, J. (1948). A Fragment on Government and an Introduction to the Principles of Morals and Legislation. (W. Harrison, Ed.). New York, NY: The MacMillan Company. (Original work published 1789). 
810 Berman, M. N. (2010). Two kinds of retributivism (Public Law Research Paper No. 171). 811 University of Texas Law.

812 Bregant, J., Shaw, A., \& Kinzler, K. D. (2016). Intuitive jurisprudence: Early reasoning about the 813 functions of punishment. Journal of Empirical Legal Studies, 13(4), 693-717. https://doi.org/10.1111/jels.12130

815

Carlsmith, K. M. (2006). The roles of retribution and utility in determining punishment. Journal 816 of Experimental Social Psychology, $\quad 42(4), \quad 437-451$. https://doi.org/10.1016/j.jesp.2005.06.007

Carlsmith, K. M. (2008). On justifying punishment: The discrepancy between words and actions. Social Justice Research, 21(2), 119-137. https://doi.org/10.1007/s11211-008-0068-x

820

Carlsmith, K. M., \& Darley, J. M. (2008). Psychological aspects of retributive justice. Advances in Experimental Social Psychology, 40, 193-236. https://doi.org/10.1016/S0065-

Carlsmith, K. M., Darley, J. M., \& Robinson, P. H. (2002). Why do we punish? Deterrence and 824 just deserts as motives for punishment. Journal of Personality and Social Psychology, 825 83(2), 284. https://doi.org/10.1037/0022-3514.83.2.284 revenge. Journal of Personality and Social Psychology, 95(6), 1316. https://doi.org/10.1037/a0012165 
829 Chavez, A. K., \& Bicchieri, C. (2013). Third-party sanctioning and compensation behavior: 830 Findings from the ultimatum game. Journal of Economic Psychology, 39, 268-277. https://doi.org/10.1016/j.joep.2013.09.004

832 Condon, P., \& DeSteno, D. (2011). Compassion for one reduces punishment for another. Journal 833 of Experimental Social Psychology, $\quad 47(3), \quad 698-701$. https://doi.org/10.1016/j.jesp.2010.11.016

835 836

837 838 839

840 841

842

843

844

845

846

847

Cooksey, R. W. (1996). Judgment analysis: Theory, methods, and applications. San Diego, CA: Academic Press.

Crockett, M. J., Özdemir, Y., \& Fehr, E. (2014). The value of vengeance and the demand for deterrence. Journal of Experimental Psychology: General, 143(6), 2279. http://dx.doi.org/10.1037/xge0000018

Dhaliwal, N. A., Patil, I., \& Cushman, F. (2021). Reputational and cooperative benefits of thirdparty compensation. Organizational Behavior and Human Decision Processes, 164, 2751. https://doi.org/10.1016/j.obhdp.2021.01.003

Dunlea, J. P., \& Heiphetz, L. (2021). Children's and adults' views of punishment as a path to redemption. Child Development, 92(4), e398-e415. https://doi.org/10.1111/cdev.13475

Eriksson, K., Andersson, P. A., \& Strimling, P. (2016). Moderators of the disapproval of peer punishment. Group Processes \& Intergroup Relations, 19(2), 152-168. https://doi.org/10.1177/1368430215583519 
848 Fraser, O. N., Koski, S. E., Wittig, R. M., \& Aureli, F. (2009). Why are bystanders friendly to 849 recipients of aggression?. Communicative \& Integrative Biology, 2(3), 285-291. https://doi.org/10.4161/cib.2.3.8718

851

852

853

854

855

856

857

858

859

860

861

862

863

864

865

866

867

868

Fry, D. P. (2000). Conflict management in cross-cultural perspective. In Natural Conflict Resolution, ed. F Aureli, FBM de Waal, pp. 334-351. Berkeley, CA: University California Press

Funk, F., McGeer, V., \& Gollwitzer, M. (2014). Get the message: Punishment is satisfying if the transgressor responds to its communicative intent. Personality and Social Psychology Bulletin, 40(8), 986-997. https://doi.org/10.1177/0146167214533130

Funk, F., \& Mischkowski, D. (2022). Examining consequentialist punishment motives in oneshot social dilemmas. Zeitschrift für Psychologie, 230(2), 127-137. https://doi.org/10.1027/2151-2604/a000459

Genevsky, A., Västfjäll, D., Slovic, P., \& Knutson, B. (2013). Neural underpinnings of the identifiable victim effect: Affect shifts preferences for giving. Journal of Neuroscience, 33(43), 17188-17196. https://doi.org/10.1523/JNEUROSCI.2348-13.2013

Gollwitzer, M., \& Denzler, M. (2009). What makes revenge sweet: Seeing the offender suffer or delivering a message? Journal of Experimental Social Psychology, 45(4), 840-844. https://doi.org/10.1016/j.jesp.2009.03.001

Gollwitzer, M., Meder, M., \& Schmitt, M. (2011). What gives victims satisfaction when they seek revenge? European Journal of Social Psychology, 41(3), 364-374. https://doi.org/10.1002/ejsp.782 
870

871

872

873

874

875

876

877

878

879

880

881

882

883

884

885

886

887

888

Gonzalez-Gadea, M. L., Dominguez, A., \& Petroni, A. (2022). Decisions and mechanisms of intergroup bias in children's third-party punishment. Social Development, 31(4), 11941210. https://doi.org/10.1111/sode. 12608

Gordon, D. S., Madden, J. R., \& Lea, S. E. (2014). Both loved and feared: Third party punishers are viewed as formidable and likeable, but these reputational benefits may only be open to dominant individuals. PloS One, 9(10), e110045. https://doi.org/10.1371/journal.pone.0110045

Gummerum, M., \& Chu, M. T. (2014). Outcomes and intentions in children's, adolescents', and adults' second-and third-party punishment behavior. Cognition, 133(1), 97-103. https://doi.org/10.1016/j.cognition.2014.06.001

Gummerum, M., López-Pérez, B., Van Dijk, E., \& Van Dillen, L. F. (2020). When punishment is emotion-driven: Children's, adolescents', and adults' costly punishment of unfair allocations. Social Development, 29(1), 126-142. https://doi.org/10.1111/sode.12387

Gummerum, M., López-Pérez, B., Van Dijk, E., \& Van Dillen, L. F. (2022). Ire and punishment: Incidental anger and costly punishment in children, adolescents, and adults. Journal of Experimental Child Psychology, 218, 105376. https://doi.org/10.1016/j.jecp.2022.105376

Gummerum, M., Van Dillen, L. F., Van Dijk, E., \& López-Pérez, B. (2016). Costly third-party interventions: The role of incidental anger and attention focus in punishment of the perpetrator and compensation of the victim. Journal of Experimental Social Psychology, 65, 94-104. https://doi.org/10.1016/j.jesp.2016.04.004 
Hamlin, J. K., Wynn, K., Bloom, P., \& Mahajan, N. (2011). How infants and toddlers react to antisocial others. Proceedings of the National Academy of Sciences, 108(50), 1993119936. https://doi.org/10.1073/pnas.1110306108

Harbaugh, W. T., Mayr, U., \& Burghart, D. R. (2007). Neural responses to taxation and voluntary giving reveal motives for charitable donations. Science, 316(5831), 1622-1625. https://doi.org/10.1126/science.1140738

Hepach, R., Vaish, A., Grossmann, T., \& Tomasello, M. (2016). Young Children Want to See Others Get the Help They Need. Child Development, 87(6), 1703-1714. https://doi.org/10.1111/cdev.12633

Hu, Y., Strang, S., \& Weber, B. (2015). Helping or punishing strangers: neural correlates of altruistic decisions as third-party and of its relation to empathic concern. Frontiers in Behavioral Neuroscience, 9, 24. https://doi.org/10.3389/fnbeh.2015.00024

Jacoby, J., Jaccard, J., Kuss, A., Troutman, T., \& Mazursky, D. (1987). New directions in behavioral process research: Implications for social psychology. Journal of Experimental Social Psychology, 23(2), 146-175. https://doi.org/10.1016/0022-1031(87)90029-1

Johnstone, G., \& Van Ness, D. (Eds.). (2013). Handbook of restorative justice. Abingdon, UK: Routledge.

Jordan, J. J., Hoffman, M., Bloom, P., \& Rand, D. G. (2016). Third-party punishment as a costly signal of trustworthiness. Nature, 530(7591), 473. https://doi.org/10.1038/nature16981

Kant, I. (1952). The critique of judgement. (J. C. Meredith, Trans.). Oxford, UK: Clarendon Press. (Original work published 1790). 
Keller, L. B., Oswald, M. E., Stucki, I., \& Gollwitzer, M. (2010). A closer look at an eye for an eye: Laypersons' punishment decisions are primarily driven by retributive motives. Social Justice Research, 23(2-3), 99-116. https://doi.org/10.1007/s11211-010-0113-4

Kenward, B., \& Östh, T. (2012). Enactment of third-party punishment by 4-year-olds. Frontiers in Psychology, 3, 373. https://doi.org/10.3389/fpsyg.2012.00373

Kenward, B., \& Östh, T. (2015). Five-year-olds punish antisocial adults. Aggressive Behavior, 41(5), 413-420. https://doi.org/10.1002/ab.21568

Kou, Y., Johansson, M., \& Verhagen, H. (2017, August). Prosocial behavior in an online game community: an ethnographic study. In Proceedings of the 12th International Conference on the Foundations of Digital Games (pp. 1-6). https://doi.org/10.1145/3102071.3102078

LaBar, K. S., \& Cabeza, R. (2006). Cognitive neuroscience of emotional memory. Nature Reviews Neuroscience, 7(1), 54. https://doi.org/10.1038/nrn1825

Lee, Y. E., \& Warneken, F. (2020). Children's evaluations of third-party responses to unfairness: Children prefer helping over punishment. Cognition, 205, 104374. https://doi.org/10.1016/j.cognition.2020.104374

Liu, X., Yang, X., \& Wu, Z. (2021). To punish or to restore: how children evaluate victims' responses to immorality. Frontiers in Psychology, 3450. https://doi.org/10.3389/fpsyg.2021.696160

Lotz, S., Okimoto, T. G., Schlösser, T., \& Fetchenhauer, D. (2011). Punitive versus compensatory reactions to injustice: Emotional antecedents to third-party interventions. 
Journal of Experimental Social Psychology, 47(2), 477-480. https://doi.org/10.1016/j.jesp.2010.10.004

Marlowe, F. W., Berbesque, J. C., Barr, A., Barrett, C., Bolyanatz, A., Cardenas, J. C., ... \& Henrich, N. (2008). More 'altruistic' punishment in larger societies. Proceedings of the Royal Society B: Biological Sciences, 275(1634), 587-592. https://doi.org/10.1098/rspb.2007.1517

Marshall, J., Gollwitzer, A., \& Bloom, P. (2022). Why do children and adults think other people punish?. Developmental Psychology, 58(9), 1783-1792. https://doi.org/10.1037/dev0001378

Marshall, J., \& McAuliffe, K. (2022). Children as assessors and agents of third-party punishment. Nature Reviews Psychology, 1-11. https://doi.org/10.1038/s44159-022$\underline{00046-y}$

Marshall, J., Yudkin, D. A., \& Crockett, M. J. (2021). Children punish third parties to satisfy both consequentialist and retributive motives. Nature Human Behaviour, 5(3), 361-368. https://doi.org/10.1038/s41562-020-00975-9

McAuliffe, K., \& Dunham, Y. (2021). Children favor punishment over restoration. Developmental science, 24(5), e13093. https://doi.org/10.1111/desc.13093

Miller, D. T., \& McCann, C. D. (1979). Children's reactions to the perpetrators and victims of injustices. Child Development, 50, 861-868. https://doi.org/10.2307/1128955 
Molho, C., Twardawski, M., \& Fan, L. (2022). What motivates direct and indirect punishment? Extending the "intuitive retributivism" hypothesis. Zeitschrift für Psychologie, 230(2), 84-93. https://doi.org/10.1027/2151-2604/a000455

Nockur, L., Kesberg, R., Pfattheicher, S., \& Keller, J. (2022). Why do we punish? On retribution, deterrence, and the moderating role of punishment system. Zeitschrift für Psychologie, 230(2), 104-113. https://doi.org/10.1027/2151-2604/a000457

Petersen, M. B., Sell, A., Tooby, J., \& Cosmides, L. (2012). To punish or repair? Evolutionary psychology and lay intuitions about modern criminal justice. Evolution and Human Behavior, 33(6), 682-695. https://doi.org/10.1016/j.evolhumbehav.2012.05.003

R Core Team (2020). R: A language and environment for statistical computing. R Foundation for Statistical Computing. Vienna, Austria. https://www.R-project.org/

Rakoczy, H., Warneken, F., \& Tomasello, M. (2008). The sources of normativity: Young children's awareness of the normative structure of games. Developmental Psychology, 44(3), 875. https://doi.org/10.1037/0012-1649.44.3.875

Raihani, N. J., \& Bshary, R. (2015a). The reputation of punishers. Trends in Ecology \& Evolution, 30(2), 98-103. https://doi.org/10.1016/j.tree.2014.12.003

Raihani, N. J., \& Bshary, R. (2015b). Third-party punishers are rewarded, but third-party helpers even more so. Evolution, 69(4), 993-1003. https://doi.org/10.1111/evo.12637

Rehren, P., \& Zisman, V. (2022). Testing the intuitive retributivism dual process model. Zeitschrift für Psychologie, 230(2), 152-163. https://doi.org/10.1027/2151-2604/a000461 
969 Riedl, K., Jensen, K., Call, J., \& Tomasello, M. (2012). No third-party punishment in 970 chimpanzees. Proceedings of the National Academy of Sciences, 109(37), 14824-14829. https://doi.org/10.1073/pnas.1203179109

972 Riedl, K., Jensen, K., Call, J., \& Tomasello, M. (2015). Restorative Justice in Children. Current 973 Biology, 25(13), 1731-1735. https://doi.org/10.1016/j.cub.2015.05.014

974 Singh, M. \& Garfield, Z. H. (2022). Evidence for third-party mediation but not punishment in 975 976 Mentawai justice. Nature Human Behaviour. https://doi.org/10.1038/s41562-022-01341$\underline{7}$

977 Sorbring, E., Deater-Deckard, K., \& Palmérus, K. (2006). Girls' and boys' perception of 978 979 980 mothers' intentions of using physical punishment and reasoning as discipline methods. European Journal of Developmental Psychology, 3(2), 142-162. https://doi.org/10.1080/17405620500398748

981

982

983

984

985

986

987

988

Stern, B. L., \& Peterson, L. (1999). Linking wrongdoing and consequence: A developmental analysis of children's punishment orientation. The Journal of Genetic Psychology, 160(2), 205-224. https://doi.org/10.1080/00221329909595393

Strobel, A., Zimmermann, J., Schmitz, A., Reuter, M., Lis, S., Windmann, S., \& Kirsch, P. (2011). Beyond revenge: neural and genetic bases of altruistic punishment. Neuroimage, 54(1), 671-680. https://doi.org/10.1016/j.neuroimage.2010.07.051

Twardawski, M., \& Hilbig, B. E. (2020). The motivational basis of third-party punishment in children. Plos One, 15(11), e0241919. https://doi.org/10.1371/journal.pone.0241919 
Tetlock, P. E. (2003). Thinking the unthinkable: Sacred values and taboo cognitions. Trends in Cognitive Sciences, 7(7), 320-324. https://doi.org/10.1016/S1364-6613(03)00135-9

Vaden, V. C., \& Woolley, J. D. (2011). Does God make it real? Children's belief in religious stories from the Judeo-Christian tradition. Child Development, 82(4), 1120-1135. https://doi.org/10.1111/j.1467-8624.2011.01589.x

Vaish, A., Carpenter, M., \& Tomasello, M. (2009). Sympathy through affective perspective taking and its relation to prosocial behavior in toddlers. Developmental Psychology, 45(2), 534-543. https://doi.org/10.1037/a0014322

Vaish, A., Herrmann, E., Markmann, C., \& Tomasello, M. (2016). Preschoolers value those who sanction non-cooperators. Cognition, 153, 43-51. https://doi.org/10.1016/j.cognition.2016.04.011

Van Doorn, J., \& Brouwers, L. (2017). Third-party responses to injustice: a review on the preference for compensation. Crime Psychology Review, 3(1), 59-77. https://doi.org/10.1080/23744006.2018.1470765

Van Doorn, J., Zeelenberg, M., \& Breugelmans, S. M. (2018). An exploration of third parties' preference for compensation over punishment: six experimental demonstrations. Theory and Decision, 85(3-4), 333-351. https://doi.org/10.1007/s11238-018-9665-9

Van Doorn, J., Zeelenberg, M., Breugelmans, S. M., Berger, S., \& Okimoto, T. G. (2018). Prosocial consequences of third-party anger. Theory and Decision, 84(4), 585-599. https://doi.org/10.1007/s11238-017-9652-6 
1009 van Prooijen, J. W. (2010). Retributive versus compensatory justice: Observers' preference for 1010 punishing in response to criminal offenses. European Journal of Social Psychology, $1011 \quad$ 40(1), 72-85. https://doi.org/10.1002/ejsp.611

1012 Will, G.-J., Crone, E. A., van den Bos, W., \& Güroğlu, B. (2013). Acting on observed social 1013 exclusion: Developmental perspectives on punishment of excluders and compensation of 1014 victims. Developmental Psychology, 49(12), 2236. https://doi.org/10.1037/a0032299

1015 Yang, X., Wu, Z., \& Dunham, Y. (2021). Children's restorative justice in an intergroup 1016 context. Social Development, 30(3), 663-683. https://doi.org/10.1111/sode.12508

1017 Yudkin, D. A., Van Bavel, J. J., \& Rhodes, M. (2019). Young children police group members at 1018 personal cost. Journal of Experimental Psychology: General. $1019 \quad$ https://doi.org/10.1037/xge0000613 